\title{
RE-DESIGN HOMESTAY LOKAL SELARAS DENGAN INDUSTRI PARIWISATA
}

\author{
I Made Juniastra \\ Program Study Teknik Industri, Fakultas Teknik, Universitas Mahendradatta \\ JI. Ken Arok No. 12 Peguyangan, Denpasar, Bali 80115 \\ Email : juniastra@gmail.com
}

\begin{abstract}
Abstrak - Untuk rumah yang berada di lokasi pariwisata, rumah tidak hanya berfungsi sebagai tempat tinggal, tapi juga mempunyai nilai ekonomis yang tinggi, yaitu bisa disewakan dan dikombinasikan dengan usaha lain sehingga memaksimalkan keuntungan. Meskipun demikian, adat dan tradisi Budaya Bali dan kearifan-kearifan lokal tetap harus dilestarikan. Desa Sanur adalah salah satu destinasi wisata di Bali yang sudah sangat terkenal sampai ke mancanegara dengan adat, tradisi, maupun keindahan alamnya. Sanur adalah kawasan wisata dimana masyarakat lokal yang sebagian besar menjadi pelaku wisata. Rumah-rumah tempat tinggal masyarakat yang merupakan tempat berkegiatan secara adat dan religi, sekaligus juga menjadi tempat usaha dibidang pariwisata ataupun fasilitas pendukung kepariwisataan. Misalnya digunakan untuk homestay termasuk fasilitas pendukungnya, seperti restoran, spa, loundry, persewaan sepeda gayung ataupun sepeda motor, dan juga kerjasama sebagai agen promosi tempat wisata lainnya. Untuk itu perlu suatu penataan yang terencana berupa masterplan dari area rumah penduduk agar tetap privasi untuk ditempati bersama keluarga, yaitu sebagai tempat berhuni serta tempat melakukan acara /upacara adat, dan juga agar mempunyai privasi bagi tamu yang menginap. Sanur Homestay adalah salah satu dari sekian banyak homestay di sanur yang dimiliki dan dikelola oleh masyarakat lokal. Dengan lahan yang cukup luas seperti umumnya lahan-lahan rumah di desa, penataan bangunan masih belum maksimal, dimana aktivitas dan sirkulasi pemilik masih berbaur dengan aktivitas dan sirkulasi tamu. Demikian juga untuk standar fasilitas akomodasi masih perlu untuk ditambahkan untuk memaksimalkan pelayanan. Perencanaan dan perancangan dilakukan dengan mendata site beserta bangunanbangunan yang ada, kemudian dikelompokkan mana bangunan yang sudah permanen dan mana yang layak untuk direnovasi. Kemudian dirancang fasilitas-fasilitas baru berupa bangunan untuk homestay, restorant, spa, front office, area servis, serta penataan site berupa kolam renang dan ruang terbuka /natah. Perancangan dilakukan dengan konsep menerapkan kaidah Arsitektur Tradisional Bali yaitu penerapan konsep Nawa Sanga pada penzoningan site dan penerapan konsep Tri Angga pada sosok tampilan bangunan, yang dikombinasikan dengan Arsitektur Tropis Modern.
\end{abstract}

Kata Kunci: homestay, arsitektur tradisional bali, tropis modern

Abstract - For a house that is in a tourism location, the house not only functions as a residence, but also has a high economic value, which can be rented and combined with other businesses so as to maximize profits. Nevertheless, the customs and traditions of Balinese Culture and local wisdom must still be preserved. Sanur Village is one of the tourist destinations in Bali which is very well known to foreign countries with its traditions and natural beauty. Sanur is a tourist area where most of the local people become tourism operators. The houses where people live are traditional and religious places of activity, as well as being a place of business in tourism or supporting tourism facilities. For example, it is used for homestays including supporting facilities, such as restaurants, spas, loundries, bicycles or motorbike rental, and also cooperation as promotion agents for other tourist attractions. For this reason, a planned arrangement is needed in the form of a master plan from the area of the resident's house so that it remains private to be occupied with the family, that is, as a place to live as well as a place to perform traditional ceremonies levents, and also to have privacy for guests who stay overnight. Sanur Homestay is one of the many homestays in Sanur that is owned and managed by the local community. With a fairly large area of land like most house land in the village, the arrangement of the building is still not optimal, where the owner's activity and circulation still mingle with the guests' activities and circulation. Likewise for the standard of accommodation facilities it still needs to be added to maximize services. Planning is done by collecting site and existing buildings data, then grouping which buildings are permanent and which ones are 
suitable for renovation. Then designed new facilities in the form of buildings for homestays, restaurants, spas, front offices, service areas, and site management in the form of swimming pools and open spaces. The design is carried out with the concept of applying the principles of Traditional Balinese Architecture, namely the application of the Nawa Sanga concept on site zoning and the application of the Tri Angga concept to the appearance figure of the building, which is combined with Modern Tropical Architecture.

Keywords: homestay, bali traditional architecture, modern tropical

\section{PENDAHULUAN}

Bali adalah pulau dengan destinasi wisata terbaik di dunia. Pertumbuhan pariwisata di Bali sangat baik dari tahun ke tahun. Demikian juga kebutuhan untuk sarana penunjangnya seperti akomodasi terus berkembang sejalan dengan pertumbuhan industri pariwisata. Masyarakat lokal haruslah menjadi subyek pembangunan tersebut sehingga masyarakat lokal bisa menikmati potensi wisata tersebut. Pariwisata di Bali sangat erat kaitannya dengan adat dan tradisi yang bersumber dari penerapan ajaran agama Hindhu yang dianut oleh mayoritas penduduk Bali. Oleh karena itu adat, tradisi, dan ritual keagamaan haruslah tetap dijaga dan diterapkan dalam keseharian masyarakat Bali. Sanur Homestay adalah salah satu contoh akomodasi wisata yang dimiliki dan dikelola langsung oleh masyarakat setempat. Dari hasil penelusuran ke site, bisa dilihat data tentang kondisi dari akomodasi tersebut, sehingga bisa meningkatkan standar dan daya jual untuk bisa tetap eksist dalam persaingan di dunia industri pariwisata. Sanur Homestay dengan tiga bangunan yang sudah dirancang khusus untuk fungsi akomodasi, dengan luasan kamar yang cukup yaitu rata-rata $16 \quad$ M2 dengan kamar mandi dalam dan ruang lemari. Pun di depan setiap kamar sudah dilengkapi teras dengan luasan rata-rata $6 \mathrm{M} 2$ dengan fasilitas meja dan kursi santai. Namun untuk bangunan lain yang disewakan masih belum layak, yaitu berupa kamar dengan luas rata-rata $10 \mathrm{M} 2$ dan kamar mandi dalam yang belum standar dalam luasan maupun penataan saniternya. Demikian juga untuk penzoningan masih bercampur antara area tamu, area suci /sanggah, maupun area untuk berhuni dan aktivitas keluarga. Adapun fungsi-fungsi yang akan ditambahkan adalah restorant beserta dapur, ruang spa, area loundry, bangunan akomodasi /kamar sewa, dan area servis lainnya.
Tujuan dari perancangan ini adalah untuk meningkatkan standar akomodasi lokal menuju ke level yang lebih baik agar tetap bertumbuh seiring perkembangan industri pariwisata, dengan penerapan kaidahkaidah Arsitektur Tradisional Bali sebagai kearifan lokal, dan dikombinasikan dengan Arsitektur Tropis Modern sesuai dengan kebutuhan fungsi dan kondisi alam di daerah tropis. Bangunan dirancang dengan ketinggian hanya dua lantai agar tetap menyatu dengan lingkungan sekitar dan penerapan Perda tentang ketinggian bangunan di Bali.

\section{METODE}

Metode yang di gunakan dalam perancangan ini adalah pengumpulan data dengan metode programatik, dan dalam tahapan perancangan menggunakan metode pragmatis. Yang dilakukan pertama adalah tahapan pengumpulan data untuk mengetahui lokasi dan potensi tapak, dan juga kebutuhan ruang yang ideal mewadahi fungsi homestay. Kemudian dilanjutkan dengan tahap analisis sintesis dengan metode pragmatis terhadap tapak dan bangunannya.

Tahap perancangan adalah tahap perumusan konsep dari analisis yang sudah di lakukan sebelumnya. Pada tahap ini dipergunakan metode pragmatis agar mendapatkan parameter yang detail tentang homestay dengan mengikuti peraturan yang ada sesuai acuan perancangan. Setelah tahapan perancangan maka didapatkan hasil desain /rancangan homestay sesuai dengan fungsi yang diwadahi dan sesuai dengan potensi tapak.

\section{HASIL DAN PEMBAHASAN Analisis Dan Konsep Tapak}

Tapak berada di jalan Danau Tamblingan, Sanur, Denpasar Timur. Luas tapak sekitar 18 Are dengan posisi di sebelah barat jalan dengan ketinggian tanah halaman adalah sama dengan jalan. di depan tapak dilintasi 
saluran pembuangan limbah DSDP. Kondisi tapak adalah kecil didepan dengan lebar sekitar $7 \mathrm{M}$ dan memanjang kebelakang, serta luas dan lebar di dalam. Didepan sudah ada bangunan bertingkat permanen yang sudah dirancang khusus untuk industri pariwisata, yaitu berupa toko dan parkir dilantai dasar, dan kamar sewa di lantai atasnya.

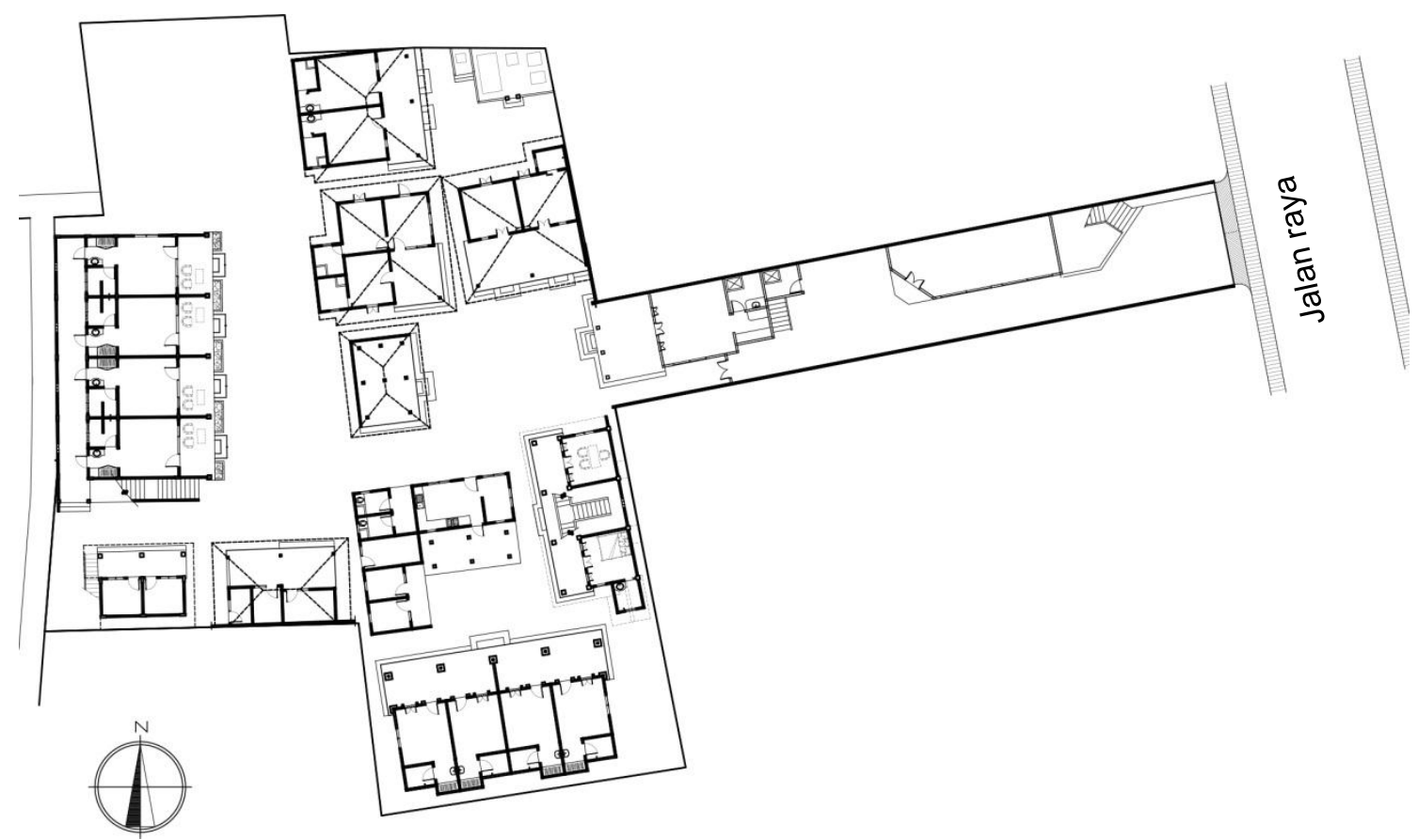

Gambar 1. Site Eksisting Sanur Homestay

Koefisien dasar bangunan (KDB) sesuai Perda idealnya adalah $60-70 \%$ dari luas tapak. Konsep perencanaan adalah dengan mengacu pada bangunan yang sudah permanen, dan sesuai space yang tersedia. Untuk bangunan yang sudah layak untuk diperbaiki akan dibongkar dan untuk diganti dengan bangunan baru.

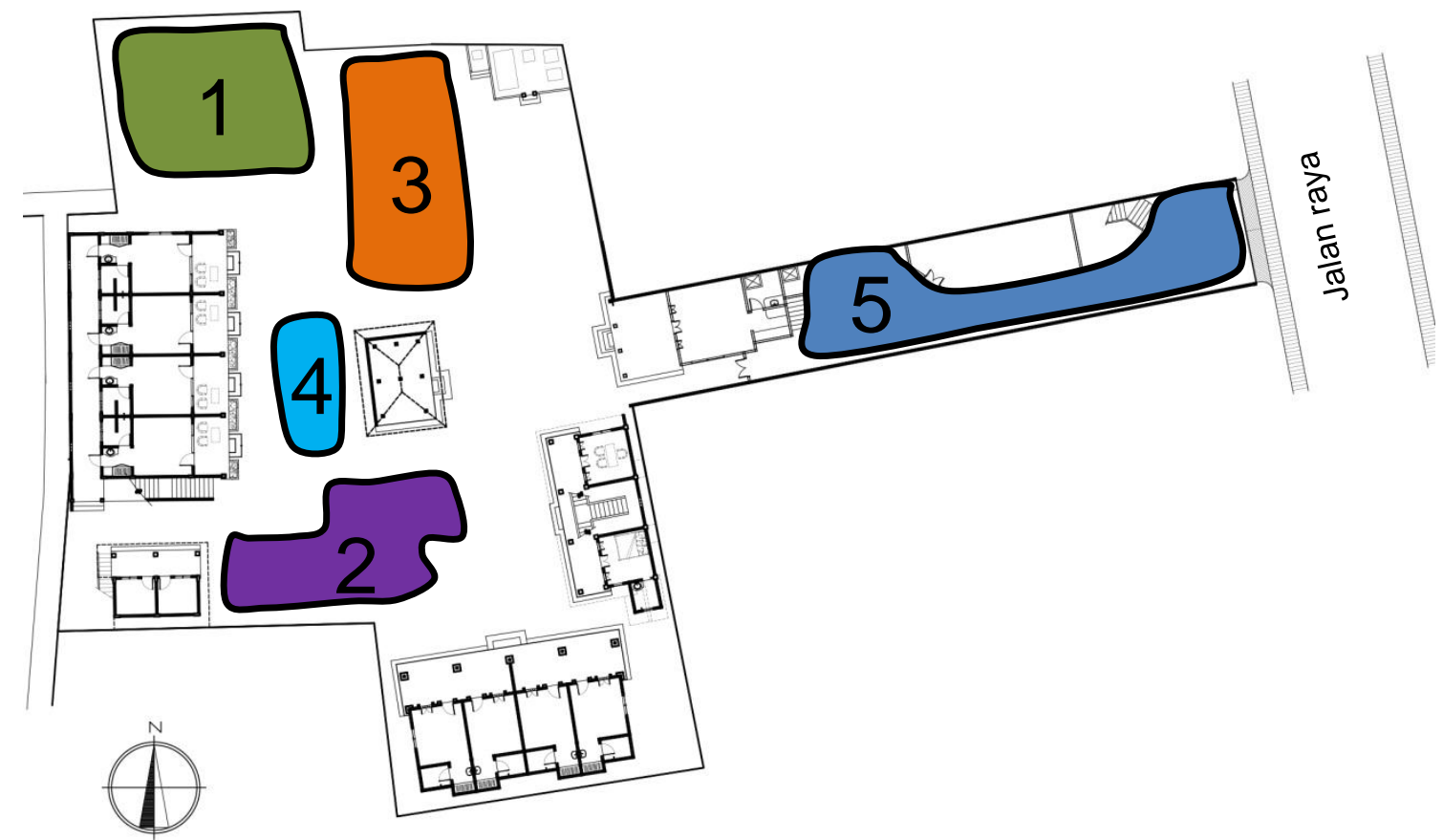

Gambar 2. Posisi Bangunan Yang Akan di Tata 


\section{Analisis Dan Konsep Kebutuhan Ruang}

Berdasarkan hasil pengumpulan data melalui interview dengan pemilik Homestay, study literature, serta study komparasi dengan bangunan akomodasi lainnya, maka didapatkan kebutuhan ruang-ruang sebagai berikut:

- Parkir

- Lobby dan Reception

- Ruang Staff Loby

- Tempat Makan /Restorant

- Dapur Homestay

- Kamar Sewa + KM /WC

- Ruang Tidur Untuk Keluarga

- Natah /Open Space Keluarga

- Ruang Spa

- Ruang Loundry + Jemur

- Ruang Staff Tinggal Dalam

- Kolam Renang
Sesuai dengan kebutuhan ruang-ruang tersebut maka bisa di kelompokkan massa bangunan sesuai dengan penzoningannya. Untuk area keluarga di pusatkan di dekat Sanggah /Tempat Suci sebagai titik mulai perancangan. Kemudian ditentukan Natah sebagai open space sebagai space penyatu di tengah-tengah tapak. Setelah itu ditentukan posisi bangunan /ruang-ruang untuk keluarga. Untuk fungsi Homestay, ditetapkan juga berupa natah /open space tersendiri sebagai pusat orientasi dengan fasilitas kolam renang sebagai view positif yang dilengkapi pool deck dan kursi santai. Bangunan-bangunan Homestay dan Restorant mengelilingi kolam renang tersebut.
Lantai 1 dan Lantai 2 Untuk Homestay /Kamar

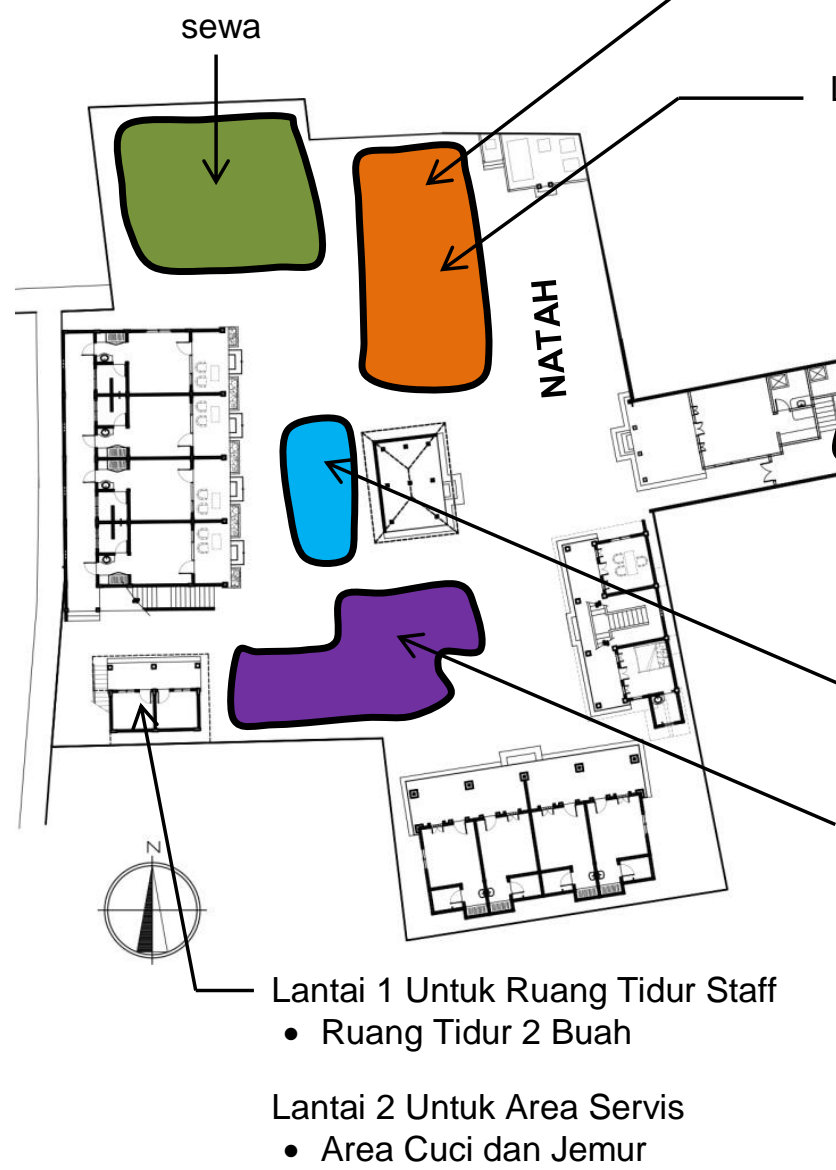

Lantai 2 Untuk Kamar Sewa /Homestay

- Ruang Tidur Sewa + KM /WC

- Foyer Sirkulasi

Lantai 1 Untuk Area Keluarga

- Ruang Tidur + KM /WC

- Ruang Keluarga

- Dapur Bersih

- Ruang Makan

Gambar 3. Penataan Massa Bangunan 


\section{Analisis Dan Konsep Pelaku, Aktivitas Dan Besaran Ruang}

Aktivitas sirkulasi pelaku di dalam tapak di polakan berdasarkan pola hierarki (konfigurasi ruang), sirkulasi dan aktivitas. Masing-masing pelaku diidentitaskan sesuai dengan fungsi dan aktivitasnya di dalam Homestay. Kemudian dari aktivitas tersebut bisa ditentukan kebutuhan ruangnya secara lebih spesifik. Kemudian langkah selanjutnya adalah menentukan faktorial dari kebutuhan ruang agar bisa ditentukan bentuk awal massa bangunan. Analisis ini berpedoman pada data dan literatur yang didapat saat pengumpulan data dengan pemilik homestay dan dikomparasi dengan literatur-literatur yang sesuai. Proses analisis dapat dilihat pada gambar berikut.

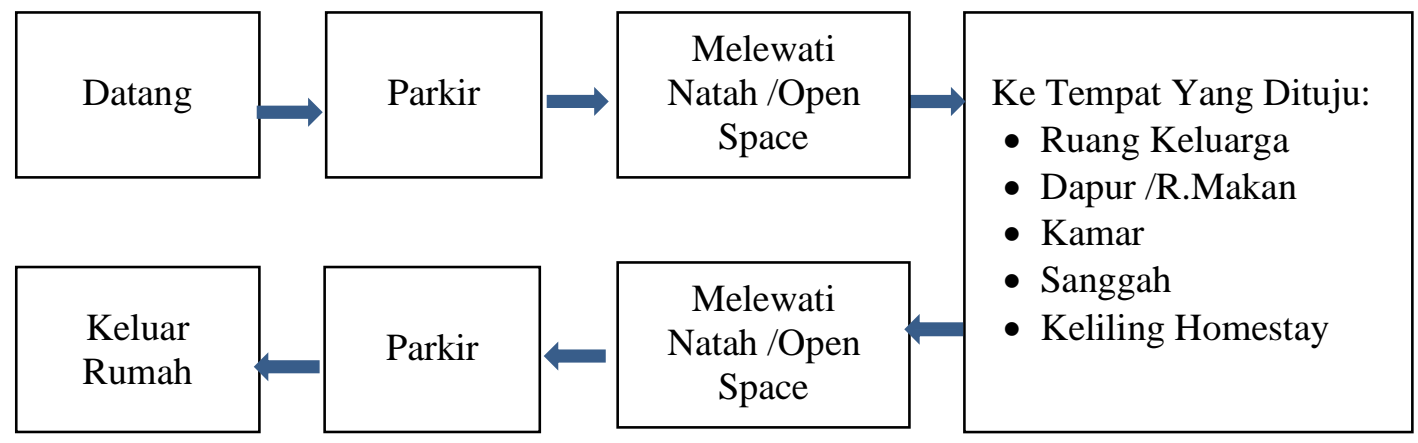

Gambar 4. Diagram Urutan Aktivitas Penghuni Rumah

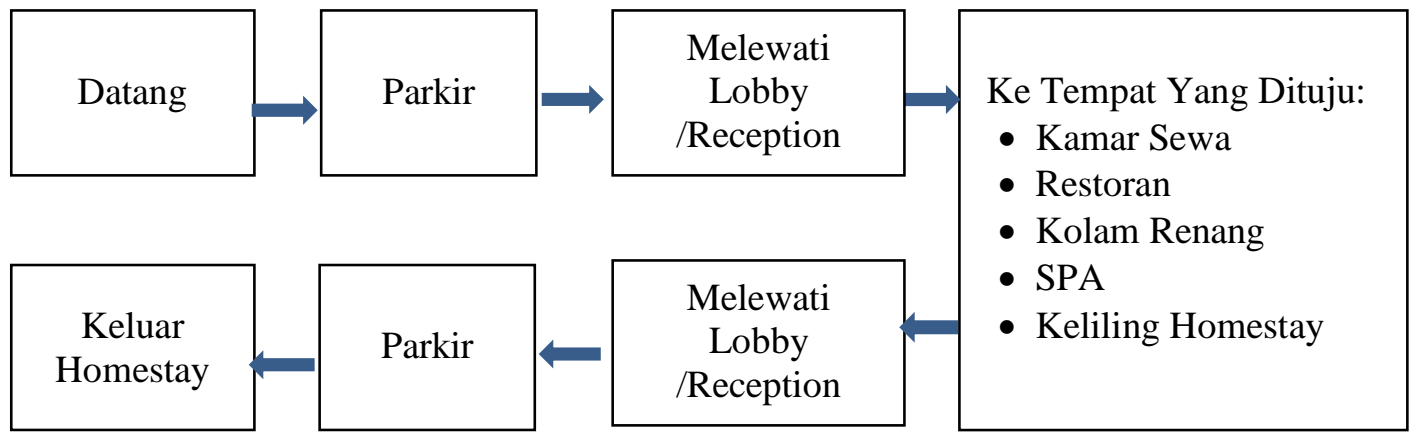

Gambar 5. Diagram Urutan Aktivitas Tamu /Pengunjung

Dari hasil pengumpulan data dari interview langsung dan beberapa literatur, diperoleh ruang ruang yang diperlukan yang tersaji dalam tabel berikut ini:

Tabel 1. Analis Pelaku, Aktivitas, Dan Besaran Ruang

\begin{tabular}{|c|c|c|}
\hline No & Nama Ruangan & Fungsi \\
\hline 1 & Area Parkir & Parkir Kendaraan \\
\hline & $\begin{array}{l}\text { Lobby } / \\
\text { dan Rua }\end{array}$ & $\begin{array}{l}\text { Area Informasi dan } \\
\text { Pendaftaran Check In } \\
\text { dan Check Out }\end{array}$ \\
\hline 3 & KM /WC Umum & $\begin{array}{l}\text { MCK Dan Ruang Ganti } \\
\text { Pengunjung Umum }\end{array}$ \\
\hline 4 & $\begin{array}{l}\text { Ruang Makan } \\
\text { /Restorant }\end{array}$ & $\begin{array}{l}\text { Tempat makan dan } \\
\text { Ngopi Santai }\end{array}$ \\
\hline 5 & Dapur Homest & $\begin{array}{l}\text { Memasak Makanan } \\
\text { Untuk Restorant /Tamu }\end{array}$ \\
\hline 6 & Ruang Tidur Staff & $\begin{array}{l}\text { Tempat Tidur Staff } \\
\text { Tetap }\end{array}$ \\
\hline 7 & SPA & Untuk Pelayanan SPA \\
\hline & Loundry & Mencuci Baju dan \\
\hline
\end{tabular}

\begin{tabular}{ccc} 
Jumlah & $\begin{array}{c}\text { Kebutuhan } \\
\text { Ruang }\end{array}$ & $\begin{array}{c}\text { Faktorial } \\
\text { Ruang }\end{array}$ \\
1 & \multicolumn{2}{c}{ Varies } \\
& $16,5 \mathrm{M} 2$ & $5,5 \times 3 \mathrm{M} 2$ \\
1 & $6 \mathrm{M} 2$ & Varies \\
1 & $33 \mathrm{M} 2$ & $6 \times 5,5 \mathrm{M} 2$ \\
1 & $30 \mathrm{M} 2$ & Varies \\
3 & $20,625 \mathrm{M} 2$ & $@ 2,5 \times 2,75$ \\
& & $\mathrm{M} 2$ \\
1 & $31,5 \mathrm{M} 2$ & $7 \times 4,5 \mathrm{M} 2$ \\
1 & $16 \mathrm{M} 2$ & $2 \times 8 \mathrm{M} 2$
\end{tabular}




\begin{tabular}{|c|c|c|c|c|c|}
\hline 9 & Area Jemur /Dry & $\begin{array}{l}\text { Peralatan Homestay } \\
\text { Menjemur Pakaian dan } \\
\text { Peralatan Homestay }\end{array}$ & 1 & $27,5 \mathrm{M} 2$ & $5 \times 5,5 \mathrm{M} 2$ \\
\hline 10 & $\begin{array}{l}\text { Kamar Tidur } \\
\text { Sewa + KM/WC }\end{array}$ & $\begin{array}{l}\text { Kamar Untuk } \\
\text { Disewakan }\end{array}$ & varies & @ 22 M2 & varies \\
\hline 11 & Kolam Renang & Berenang, View Positif & 1 & $21 \mathrm{M} 2$ & $7 \times 3 \mathrm{M} 2$ \\
\hline 12 & Pool Deck & $\begin{array}{l}\text { Area Duduk Di pinggir } \\
\text { Kolam Renang }\end{array}$ & 1 & $30 \mathrm{M} 2$ & Varies \\
\hline 13 & Ruang Keluarga & $\begin{array}{l}\text { Berkumpul Keluarga, } \\
\text { Nonton TV, DII }\end{array}$ & 1 & $15 \mathrm{M} 2$ & $3,75 \times 4 \mathrm{M} 2$ \\
\hline 14 & Dapur Keluarga & $\begin{array}{l}\text { Memasak Untuk } \\
\text { Keluarga }\end{array}$ & 1 & $8 \mathrm{M} 2$ & $2,5 \times 3,2 \mathrm{M} 2$ \\
\hline 15 & Ruang makan & $\begin{array}{l}\text { Tempat makan } \\
\text { Keluarga }\end{array}$ & 1 & $10 \mathrm{M} 2$ & $4 \times 2,5 \mathrm{M} 2$ \\
\hline 16 & Teras Keluarga & $\begin{array}{l}\text { Teras Tempat } \\
\text { Berkumpul Keluarga }\end{array}$ & 1 & $11,25 \mathrm{M} 2$ & $3,75 \times 3 \mathrm{M} 2$ \\
\hline 17 & $\begin{array}{l}\text { Ruang Tidur } \\
\text { Untuk Keluarga + } \\
\text { KM NC Dalam + } \\
\text { Ruang Lemari }\end{array}$ & $\begin{array}{l}\text { Tempat Tidur Bagi } \\
\text { anggota Keluarga }\end{array}$ & Varies & $23 \mathrm{M} 2$ & Varies \\
\hline 18 & Natah & Open Space & 1 & \multicolumn{2}{|c|}{ Varies } \\
\hline 19 & $\begin{array}{l}\text { Sanggah /Tempat } \\
\text { Suci }\end{array}$ & Tempat Sembahyang & 1 & \multicolumn{2}{|c|}{ Sesuai Semula (Eksisting) } \\
\hline 20 & Bale Dangin & Untuk Banten Upacara & 1 & \multicolumn{2}{|c|}{ Sesuai Semula (Eksisting) } \\
\hline
\end{tabular}

Dari gambar penzoningan massa bangunan diatas, perlu dilakukan pembangunan 3 (tiga) massa bangunan baru untuk menampung aktivitas Homestay. Dari hasil analisa dan konsep diatas, didapat tatanan ruang dan tampilan bangunan sebagai berikut.
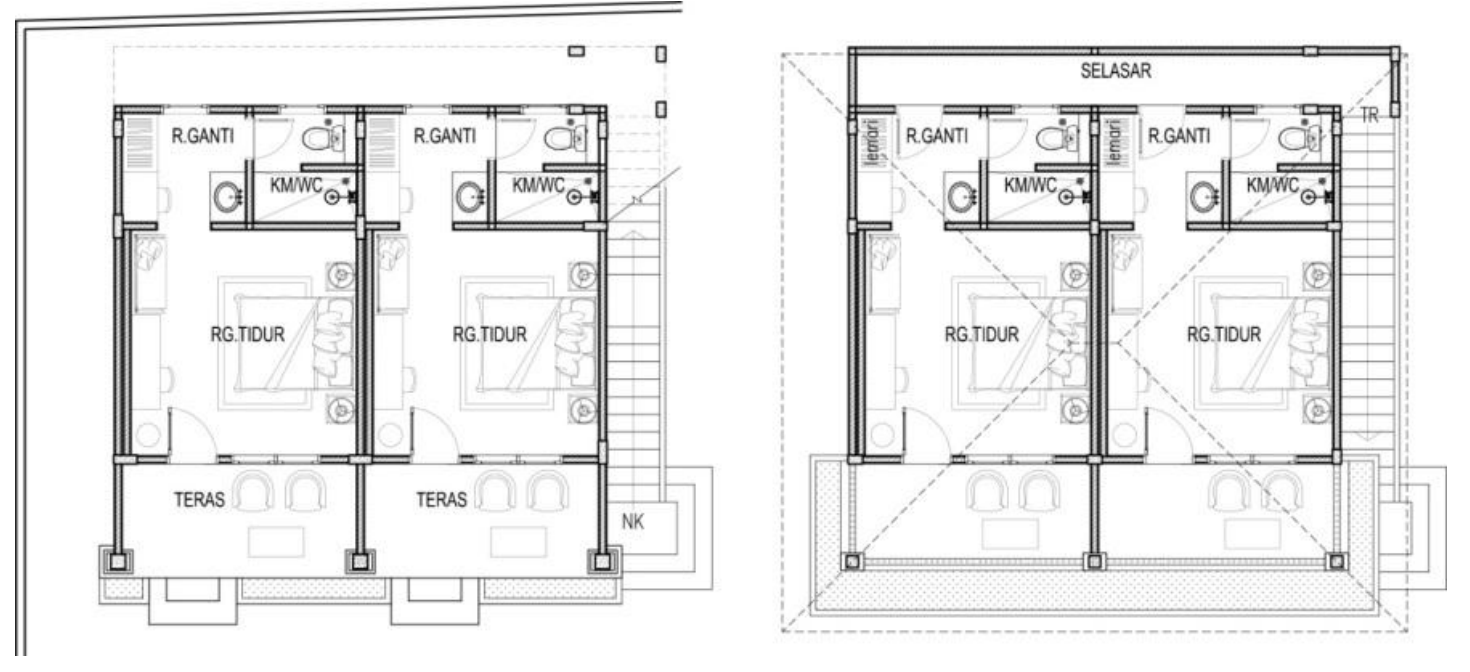

Gambar 6. Denah Lantai 1 dan Denah Lantai 2 (Bangunan 1) 

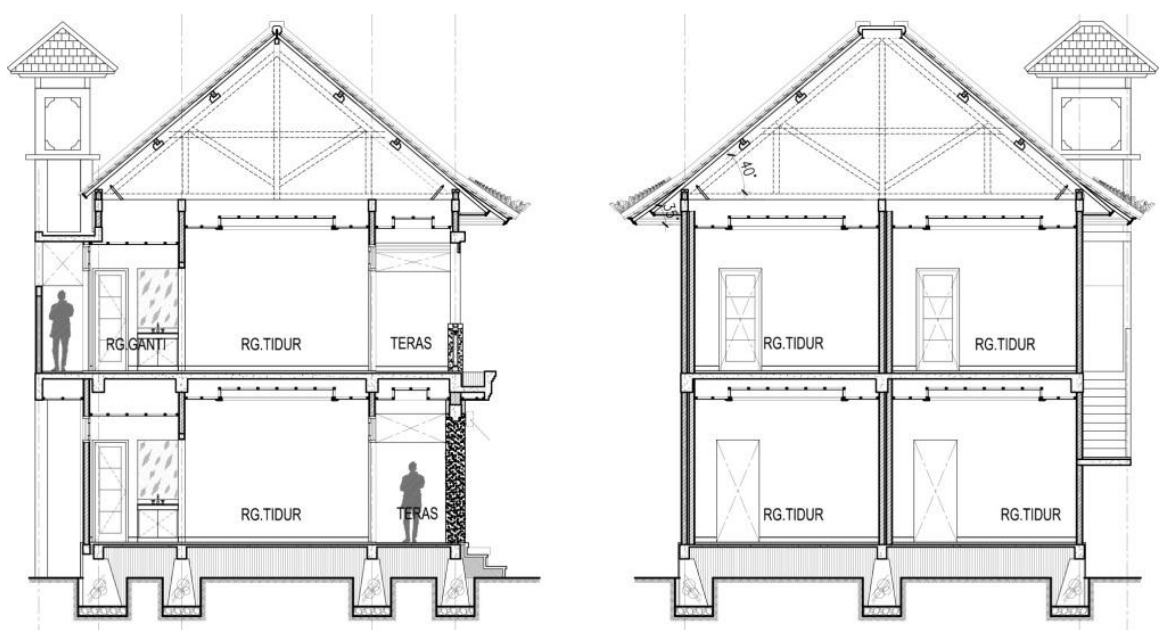

Gambar 7. Potongan A-A dan Potongan B-B (Bangunan 1)
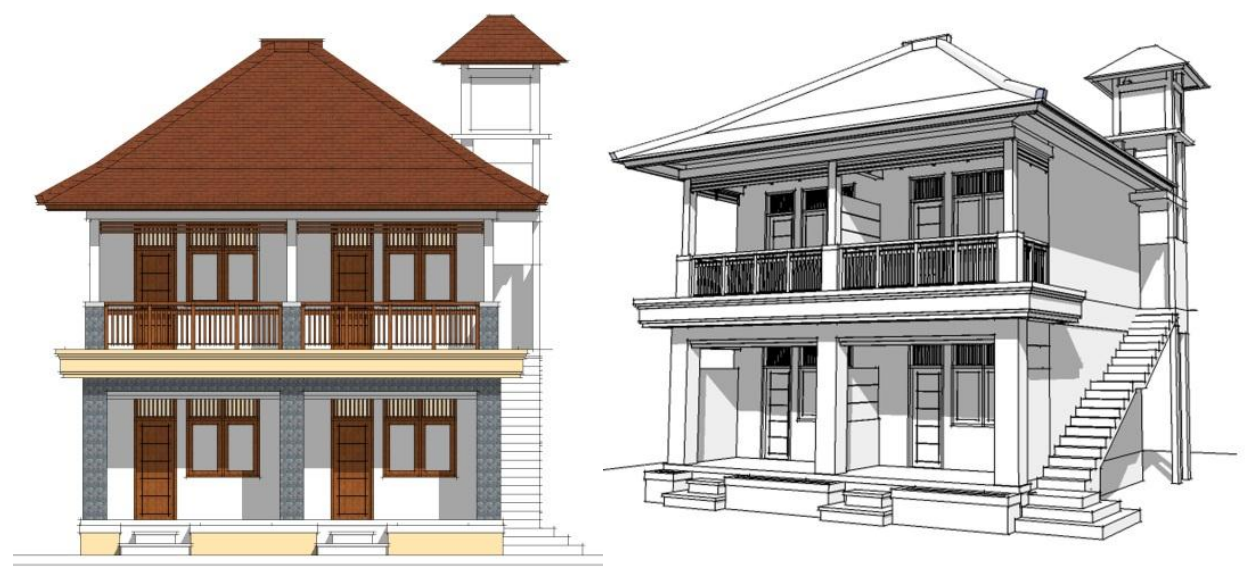

Gambar 8. Tampilan Depan dan Tampilan Perspektif (Bangunan 1)

\section{Bangunan 2}

Bangunan yang ke dua ini direncanakan untuk menampung fungsi Lobby dan Reception, Tempat Makan /Restorant, Dapur homestay, KM NC Umum, serta
Kamar Tidur Staff untuk dilantai 1 (satu). Sedangkan untuk di lantai 2 (dua) direncanakan untuk menampung fasilitas Kamar Sewa + KM MC Dalam, Fasilitas SPA, dan Area Jemur ditempat terpisah.

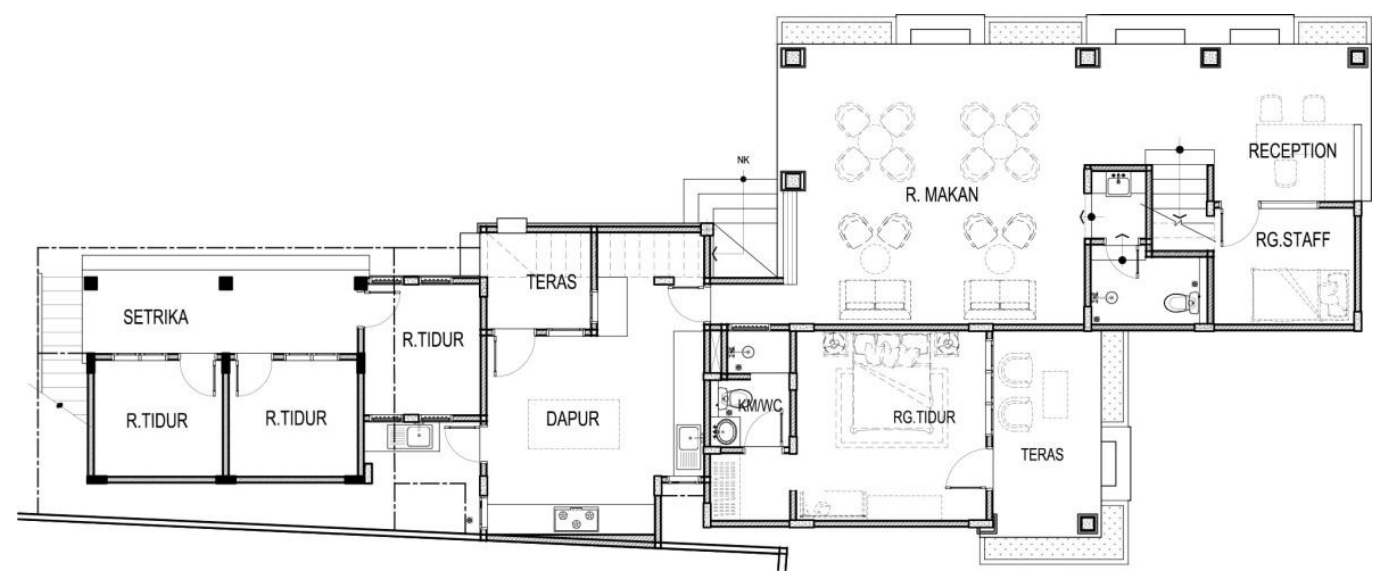

Gambar 9. Denah Lantai 1 (Bangunan 2) 


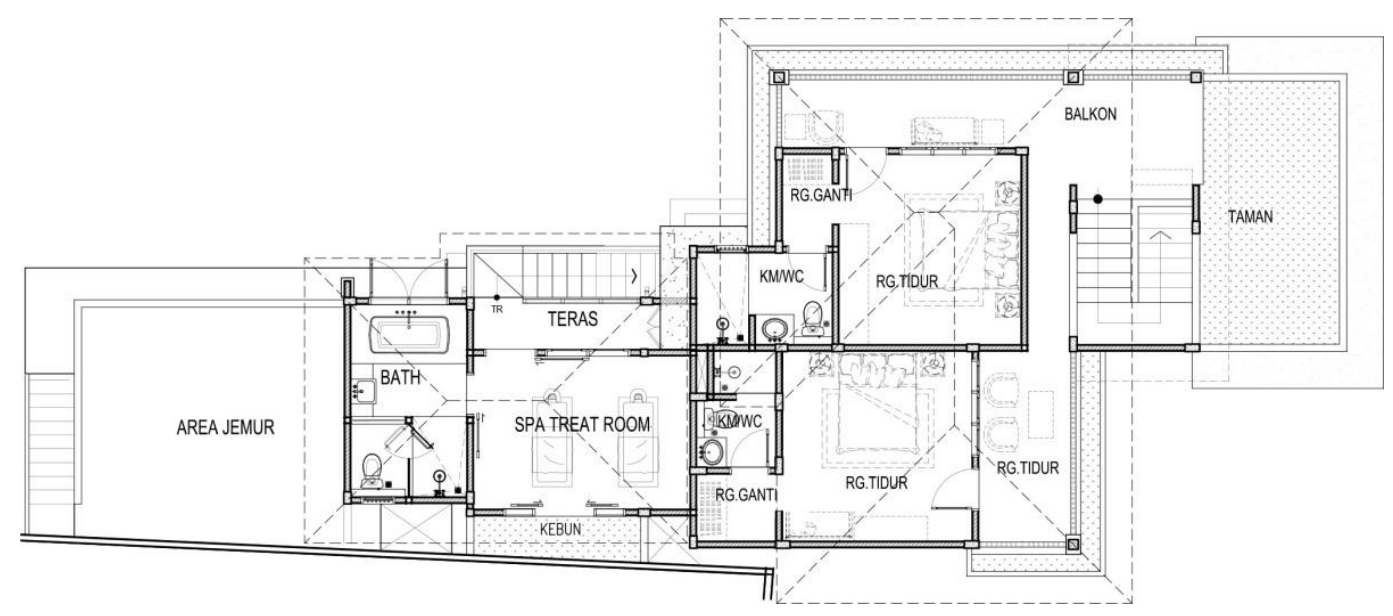

Gambar 10. Denah Lantai 2 (Bangunan 2)
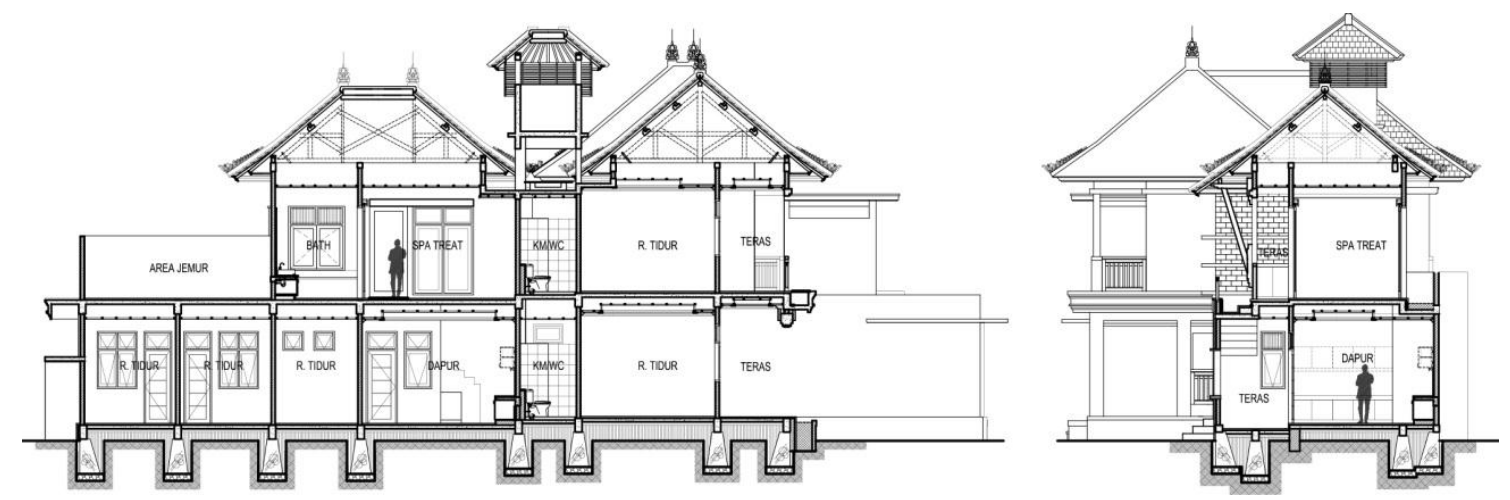

Gambar 11. Potongan A-A dan Potongan B-B (Bangunan 2)

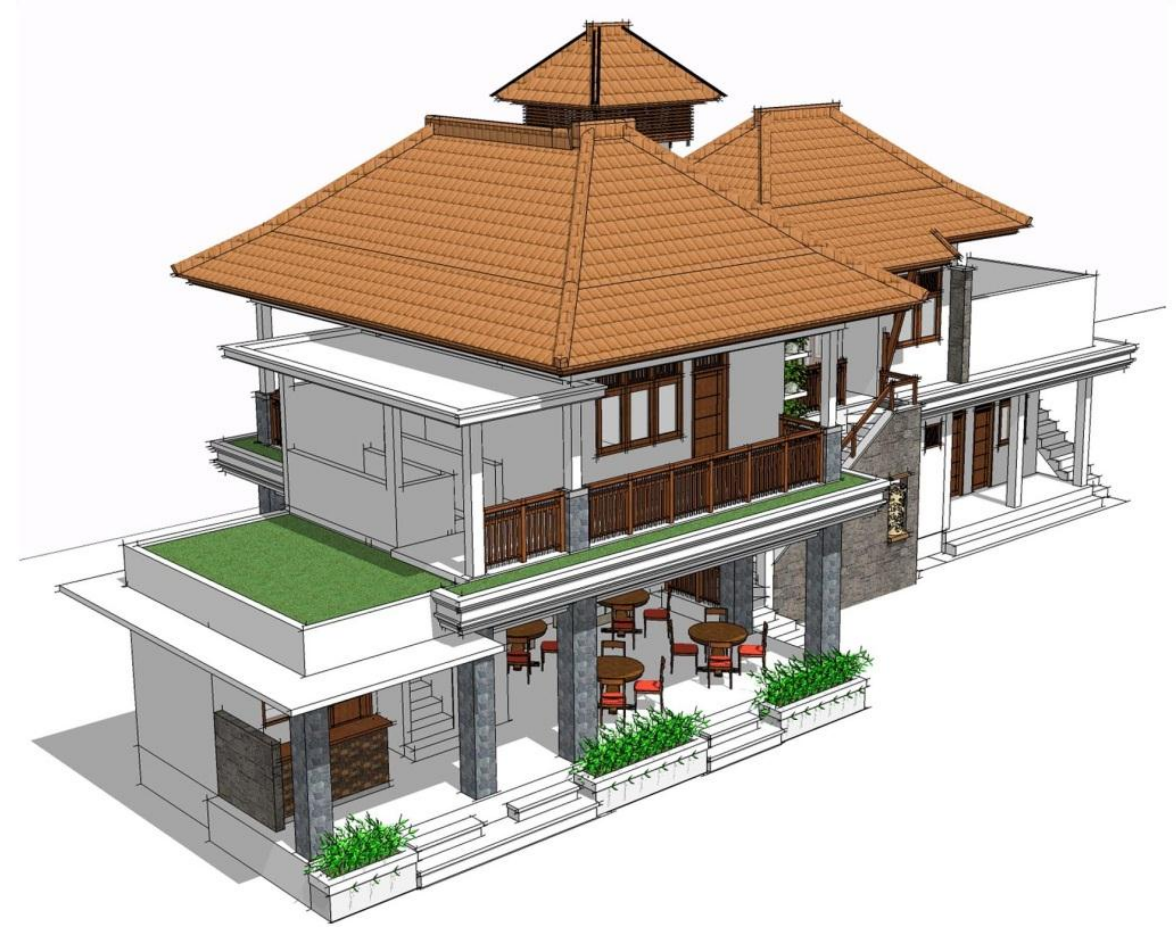

Gambar 12. Tampilan Perspektif (Bangunan 2) 


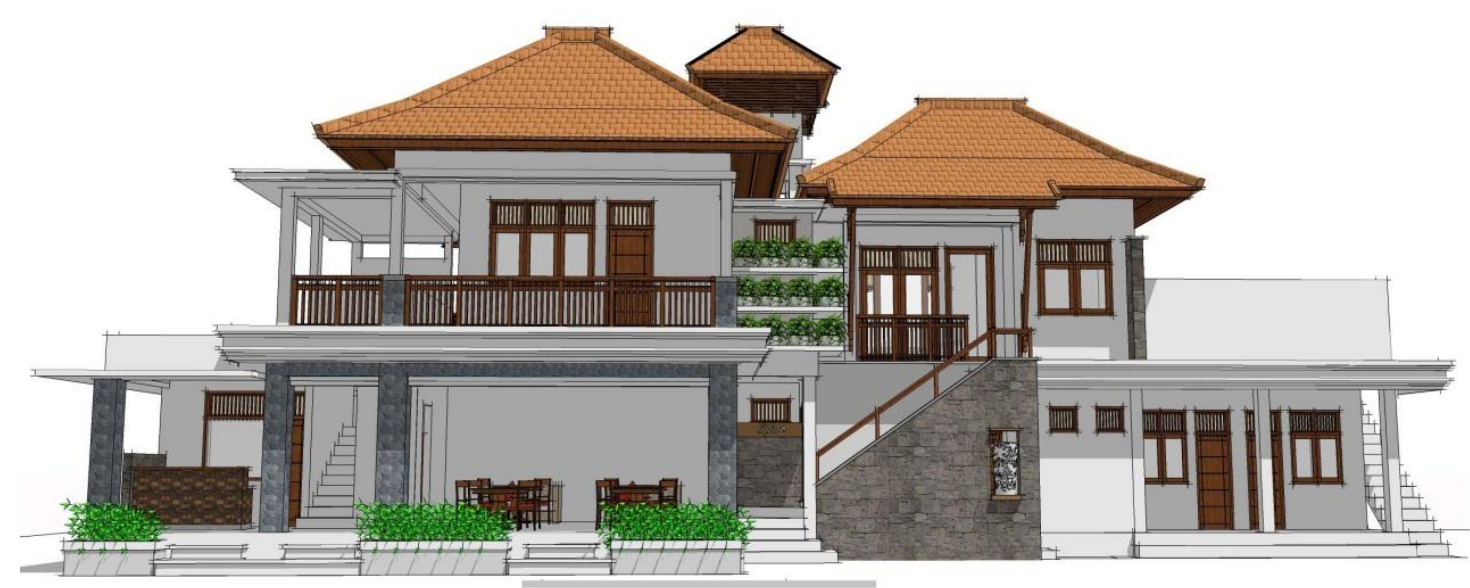

Gambar 13. Tampilan Depan (Bangunan 2)

\section{Bangunan 3}

Bangunan yang ke tiga ini terletak di samping tempat suci /Sanggah dan juga di samping Bale Dangin sehingga sangat tepat untuk menampung fungsi sebagai rumah tinggal keluarga di lantai 1 (satu). Arah orientasi dari lantai 1 adalah ke Natah /Open Space sekaligus sebagai area penghubung area Tempat Tinggal

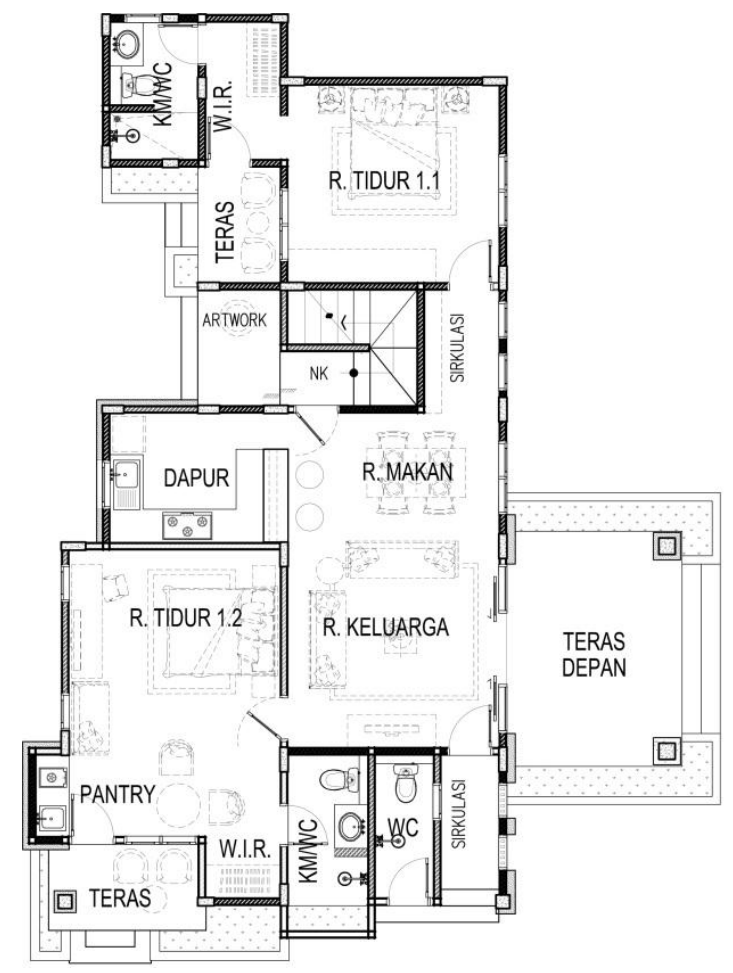

Keluarga, Sanggah, Bale Dangin, dan juga Ruang Tidur Keluarga di bangunan eksisting yang sudah direncanakan. Untuk lantai 2 (dua) arah orientasinya adalah ke arah Kolam Renang yang sekaligus berfungsi sebagai Natah Homestay. Lantai 2 (dua) bangunan ini difungsikan untuk Kamar Sewa sehingga sirkulasinya tidak mengganggu aktivitas privat keluarga.

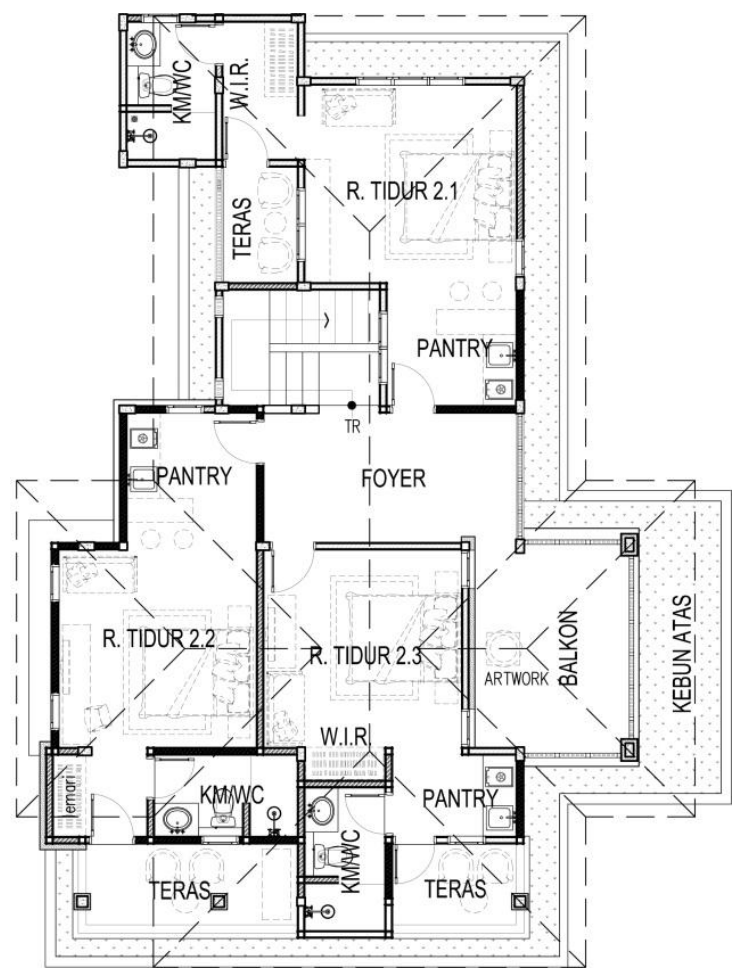

Gambar 14. Denah Lantai 1 dan Denah Lantai 2 (Bangunan 3) 

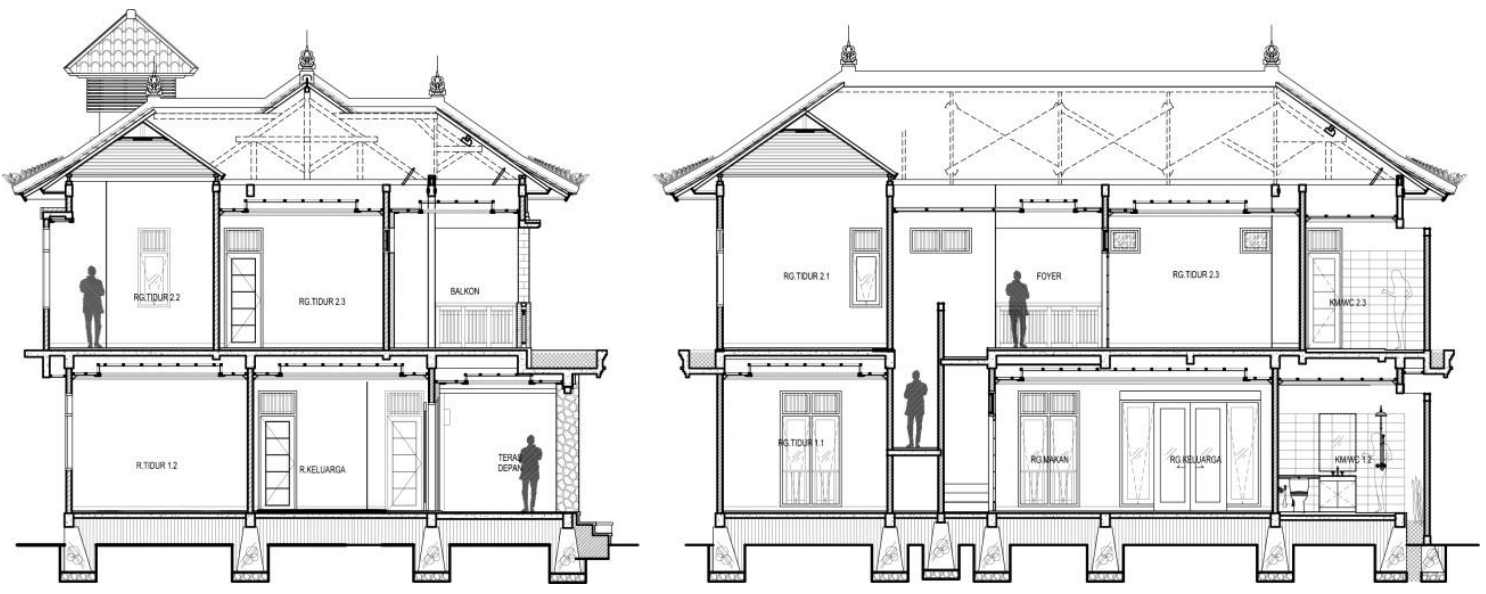

Gambar 15. Potongan A-A dan Potongan B-B (Bangunan 3)
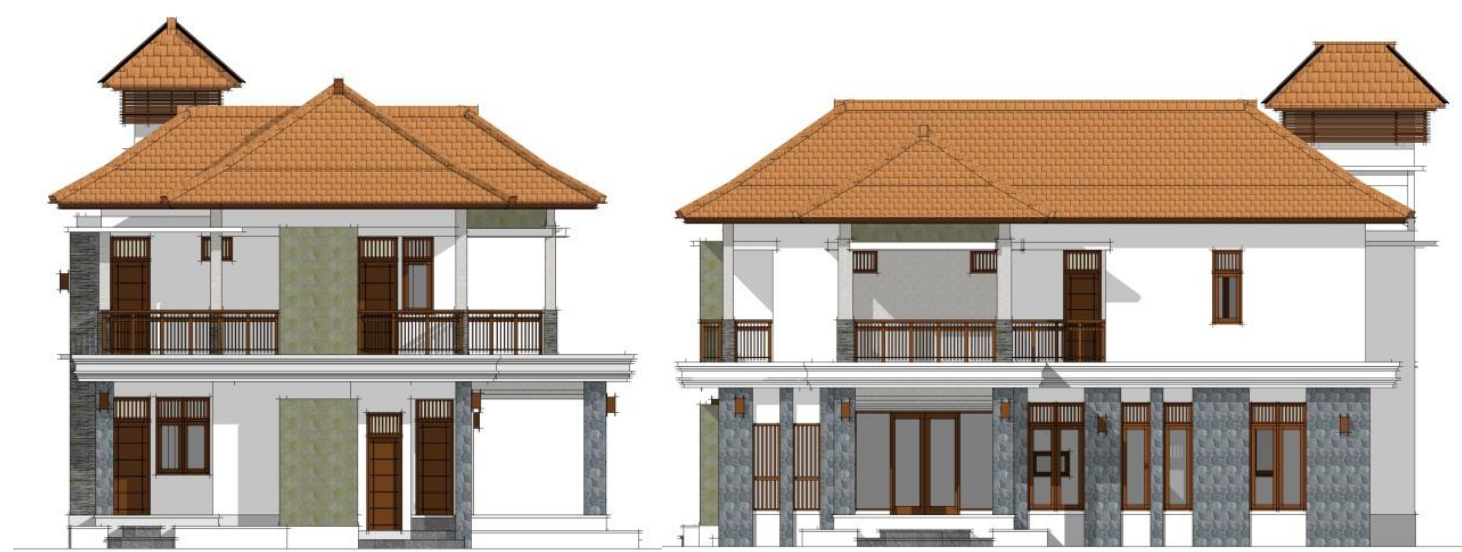

Gambar 16. Tampilan depan dan Tampilan Samping (Bangunan 3)

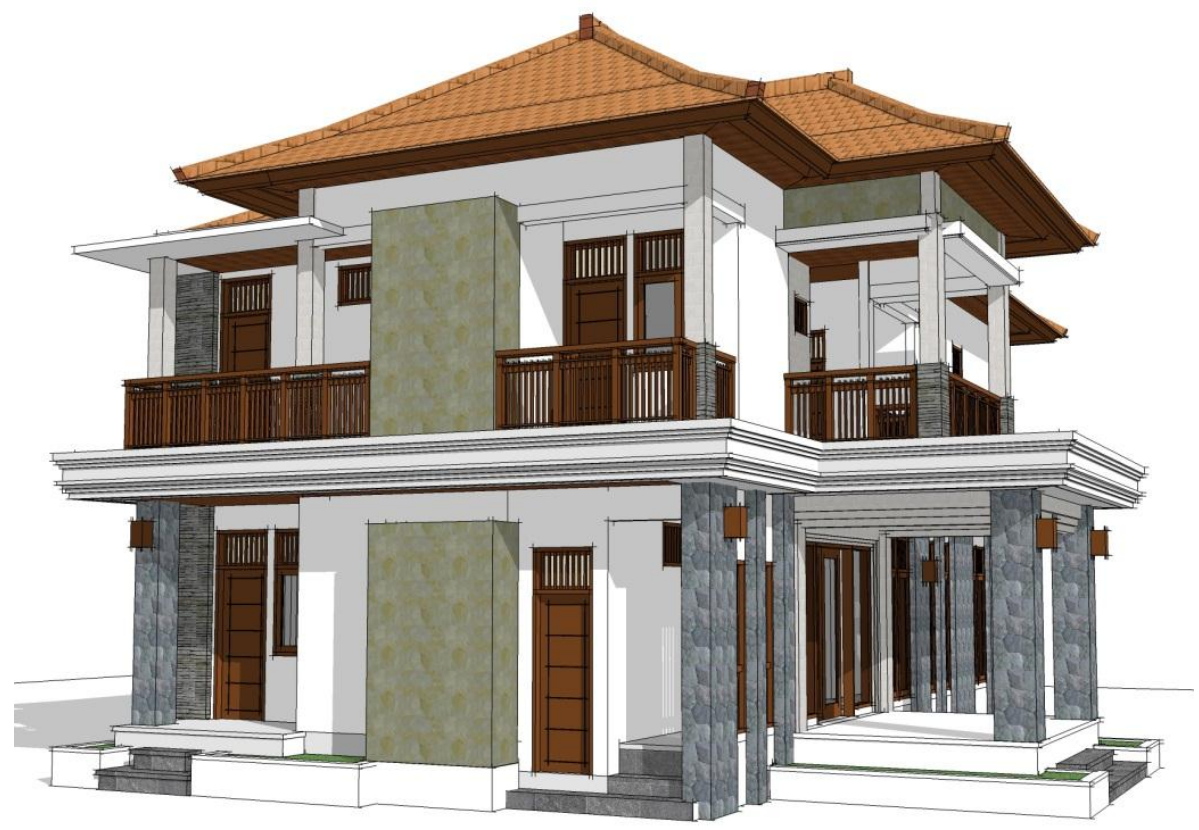

Gambar 17. Tampilan Perspektif (Bangunan 3) 


\section{Analisis dan konsep ruang dalam}

Konsep ruang dalam didesain sedemikian rupa untuk kenyamanan dan keamanan di dalam ruangan. Pencahayaan dan penghawaan alami tetap rencanakan walaupun dalam penggunaannya bisa di buka dan ditutup sesuai dengan kondisi cuaca di luar. Untuk penataan mebleair sebagian besar menggunakan bahan dari kayu jati yang sudah kering sehingga awet dan minim perawatan. untuk mebel dan kusen menggunakan warna alami kayu yaitu coklat. Untuk cat tembok dan plafon menggunakan warna cerah dominan putih agar terkesan bersih dan tenang. Tampilan interior direncanakan sederhana namun tepat dalam penataannya sehingga kekuatan karakter bahan bisa tampil dengan maksimal. Disamping itu juga untuk menekan biaya agar efisien karena akan berpengaruh juga pada penetapan harga agar bisa tetap eksis dalam dunia industri pariwisata.

\section{Analisa dan konsep tampilan}

Untuk bentuk dan tampilan bangunan menerapkan Konsep Tri Angga dengan membandingkan bentuk tubuh manusia yang terdiri dari kepala, badan, dan kaki karena tapak berada di Daerah Bali yang terikat oleh perda tentang Arsitektur Tradisional Bali.. Konsep ini akan di transformasikan ke dalam wujud bentuk dan tampilan bangunan yang juga mempunyai unsur kepala, badan, dan kaki. Unsur kepala adalah atap dari bangunan dalam hal ini agar memakai atap dengan bentuk limasan dengan kemiringan sudut tertentu $\left(38^{\circ}-40^{\circ}\right)$ yang proporsi dengan tinggi dan lebar bangunan.

\section{Pembahasan Hasil Desain}

Homestay adalah rumah tinggal yang sebagian disewakan juga untuk sarana akomodasi, baik disewakan harian ataupun dalam jangka waktu tertentu.

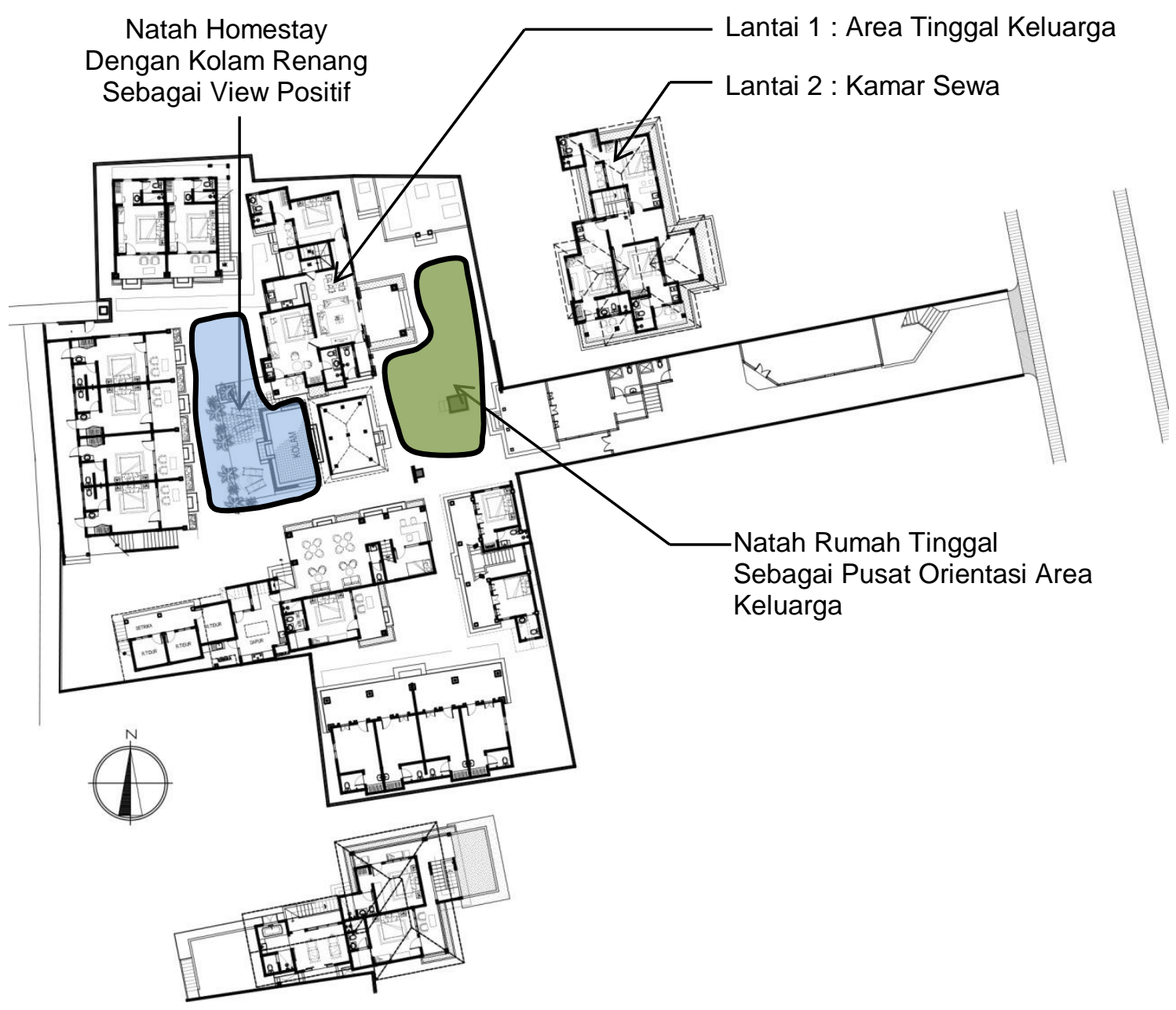

Gambar 18. Rancangan Masterplann Kawasan 
Sanur Homestay dimiliki oleh masyarakat lokal Desa Sanur yang melihat peluang dari perkembangan pariwisata di daerahnya. Namun dengan potensi yang tersedia perlu dilakukan redesain atau masterplanning dari homestay miliknya agar memenuhi standar akomodasi homestay, pun juga agar tetap nyaman dan privasi sebagai tempat tinggal bersama keluarga.

Dari masterplann diatas biasa terlihat penataan massa bangunan dan penzoningan ruang-ruang publik dan privat. Area pribadi sebagai tempat berhuni keluarga mempunyai natah /open space sebagai pusat orientasi dan sirkulasi antara ruang keluarga satu dengan ruang keluarga lainnya. Dan untuk fungsi homestay mempunyai natah /open space tersendiri juga sebagai pusat orientasi. Dengan adanya pemisahan orientasi dan sirkulasi ini maka baik keluarga maupun homestay akan mempunyai privasi sendiri-sendiri. Kaidah Arsitektur Tradisional Bali sebagai kearifan lokal yang merupakan sumber dari kekuatan pariwisata Bali tetap diterapkan baik pada penataan ruang (konsep nawa sanga - hulu-teben) maupun pada tampilan bangunan (konsep tri angga). Pada pintu masuk dari tiap-tiap bangunan selalu dilengkapi teras depan, yang berfungsi sebagai ruang perantara antara ruang luar dengan ruang dalam bangunan. Penyelarasan tampilan bangunan dengan karakter lingkungan Bali dirancang dengan penerapan bahan-bahan alami setempat disertai dengan tempelan material bernuansa alam yang umumnya ditampilkan karakter alamiahnya, diantaranya, tempelan batu kali random, batu jogja, paras silakarang random, pilah jember dengan pemasangan susun sirih, kayu bangkirai, dan lambersering seseh dengan finishing natural dan kombinasi warna coklat pada bagian kayu. Bukaanbukaan jendela yang lebar dikombinasi dengan ventilasi bagian atasnya untuk memanfaatkan pencahayaan alami dan penghawaan alami.

\section{KESIMPULAN}

Dalam perencanaan dan perancangan homestay, hal-hal yang harus diperhatikan adalah:

- Merancang masterplann sebagai arah pembangunan dan perkembangannya kedepan. Pembangunan bisa dilakukan secara bertahap sesuai dengan ketersediaan dana dan skala prioritas pembangunan.

- Tahap pengumpulan data mesti dilakukan secara teliti dan mendetail untuk mengumpulkan data, baik tentang potensi tapak, kebutuhan ruang, ataupun ada hal-hal khusus tertentu yang harus diperhatikan baik melalui wawancara langsung dengan pemilik, melalui study literatur, dan juga study komparasi dengan bangunan akomodasi lainnya yang sejenis.

- Dalam perencanaan akomodasi homestay tetap harus berpedoman pada kaidah Arsitektur Tradisional Bali sebagai kearifan lokal yang merupakan sumber kekuatan pariwisata Bali, walaupun dalam penerapannya dikombinasikan dengan Arsitektur Tropis Modern untuk memenuhi kebutuhan standar akomodasi.

- Dalam penataan massa bangunan, penzoningan ruang-ruang tetap harus berpedoman pada konsep Nawa Sanga /Hulu-Teben.

- Dalam merancang tampilan bangunan berpedoman pada konsep Tri Angga yaitu pembagian bangunan menjadi bagian kepala, badan, dan kaki.

\section{DAFTAR PUSTAKA}

Glebet I Nyoman,dkk. 1986. Arsitektur Tradisional Daerah Bali. Denpasar: Depdikbud Propinsi Bali.

Juniastra I Made. 2019. Perancangan Gedung Laboratorium Sebagai BagianTerintegrasi Rumah Sakit. Bali. Prosiding Seminar Semarayana Undwi. 